\title{
Comparison of changes in 2015 to 2019 for socioeconomic inequalities and inequities in health services utilization among patients with hypertension in Pearl River Delta Region of China
}

\section{Yan Liu}

School of Public Health, Guangzhou Medical University

\section{Mengjiao Cheng}

School of Public Health, Guangzhou Medical University

\section{Xin Peng}

School of Public Health, Guangzhou Medical University

Junxuan Huang

School of Public Hrealth, Guangzhou Medical University

Nan Liu

Pinghu Hospital, Health Science Center, Shenzhen University

Jinxiang Ma

School of Public Health, Guangzhou Medical University

Peixi Wang ( $\sim$ peixi001@163.com)

Guangzhou University https://orcid.org/0000-0001-5177-1479

\section{Research}

Keywords: Health service utilization, Hypertension, Socioeconomic inequality, Horizontal inequity, China

Posted Date: October 9th, 2020

DOI: https://doi.org/10.21203/rs.3.rs-88087/v1

License: (c) (i) This work is licensed under a Creative Commons Attribution 4.0 International License. Read Full License 
Comparison of changes in 2015 to 2019 for socioeconomic inequalities and inequities in health services utilization among patients with hypertension in Pearl River Delta Region of China

\author{
Yan Liu MD ${ }^{1,3}$ \\ Mengjiao Cheng MD ${ }^{1}$ \\ Xin Peng MD ${ }^{1}$ \\ Junxuan Huang MD \\ Nan Liu MD, Ph.D ${ }^{2}$ \\ Jinxiang Ma MD Ph.D ${ }^{1 *}$ \\ Peixi Wang MD, Ph.D ${ }^{3 *}$
}

${ }^{1}$ School of Public Health, Guangzhou Medical University, Guangzhou, Guangdong, China

${ }^{2}$ Pinghu Hospital, Health Science Center, Shenzhen University, Shenzhen,

Guangdong, China 
${ }^{3}$ General Practice Center, The Seventh Affiliated Hospital of Southern Medical University, Foshan, Guangdong, China

First author: Yan Liu, Email: 13350819519@163.com

*Corresponding author: Peixi Wang, Email: peixi001@163.com

Jinxiang Ma, Email:_mjx777108@ hotmail.com

Co-authors: Mengjiao Cheng, Email: 15700727758@ 163.com

Xin Peng, Email: 609167985@qq.com

Junxuan Huang, Email:_circle_wong@ yeah.net

Nan Liu, Email: 13688869875@163.com

\begin{abstract}
Background: Assessing inequities in health services utilization contributes to build effective strategies for promotion of health equity.


This study aimed to evaluate the socioeconomic inequalities and inequities in health services utilization among hypertensive patients and explore the changes between 2015 and 2019 in Pearl River Delta region of China. Methods: The cross-sectional surveys were conducted using the questionnaire. In total, 830 and 1166 hypertensive patients in 2015 and 2019 were interviewed, respectively. The concentration index (CI) and the horizontal inequity (HI) were used to access the socioeconomic inequalities and inequities in health services use. The contribution of influential factors to the overall unfairness was estimated via the concentration index decomposition. Oaxaca-type decomposition technique was utilized to measure the changes in socioeconomic inequalities between the observation periods. Results: From 2015 to 2019, the CIs for outpatient and inpatient utilization decreased from 0.1498 to $0.1198,0.1982$ to 0.1648 , respectively, and the HIs for outpatient and inpatient utilization decreased from 0.1478 to 0.1078 , 0.1956 to 0.1390 , respectively, i.e. obvious pro-rich inequities in utilization of health services by hypertensive patients existed in Pearl River Delta Region even after controlling different needs, but they decreased over time. The inequities in inpatient utilization were higher compared with that in outpatient utilization. Economic status contributed the maximum ratio of the socioeconomic inequalities in the use of health 
services in these two years $(107.54 \%$ in $2015,106.92 \%$ in 2019$)$. Oaxaca decomposition revealed that factors such as residential location, registration, health insurance and time to the nearest health facilities, employment status and educational level, etc. made positive contributions to decline the inequalities. While factors pushed the equalities toward deterioration included health needs, economic status and household size. Conclusion: There were certain decline in the socioeconomic inequalities and inequities in health services utilization by hypertensive patients in Pearl River Delta Region of China by comparison of 2015 and 2019. Although the pro-rich inequities persists, it does suggest that government policies have improved health equity over time.

Keywords: Health service utilization, Hypertension, Socioeconomic inequality, Horizontal inequity, China

\section{Introduction}

Inequality in health service utilization, it rises a constant concern of health system in the world[1], which means that the differences access to health service between social class, such that one group is better off than another[2-4]. When different demands have been adjusted, the existing inequality can be interpreted as inequity[4]. 
Inequity in health care utilization is one kind of avoidable inequality[5]. However, this inequality has been experienced and observed globally[5-7], despite overall improvement of health system in recent decades. Such inequality even exists in nations which are considered as "more equitable", such as Norway[8]. China, as the greatest developing country, is no exception. In the report published by the World Health Organization in 2000 , China ranked $188^{\text {th }}$ out of 191 countries in health performance[9]. Indeed, its rapid development of economic and health care have not been distributed evenly, leading to a widening gap between the rich and poor and the increased inequality in health services utilization[10,11]. Fortunately, the severity of these unbalance of social and economic development drew attentions by Chinese government by adoption and implementation relevant policies, such as launching new reform of health care system in 2009 to ensure equitable accessibility of health services. The number of occupational (assistant) physicians per thousand increased by $48 \%$ from 2009 (1.75) to 2018 (2.59), which was one of the results of this reform[12].

Study have demonstrated that people with chronic non-communicable diseases (NCDs) are particularly vulnerable to the inequalities in utilization of health services due to the long-term use of health care[10], and the significant inequalities favor the rich[13]. 
Hypertension, as one of the most common NCDs, is associated with 7.6 million deaths per year in the world (13.5\% of all deaths) and it costs $10 \%$ health care expenditures in hypertension and its complications[14, 15]. More seriously, the number of people suffering from hypertension is still on the rise, with an estimated 1.56 billion (29.2\%) worldwide by 2025 [16]. In China, it has reported that the prevalence of hypertension has reached $30 \%$ in adults and $6.6 \%$ of health-care costs is directly associated with hypertension[17, 18]. Compared with other diseases, patients with hypertension often require more frequent and long-term connecting to health facilities. It has been considered as one significant financial burden to the low socioeconomic groups and they tend to less health services, which will exacerbate the inequalities in the utilization of health services. Existing researches have already showed the inequalities in access to health services among patients with NCDs[10, 19]. However, few reports are concerning about the changes of the inequalities and the associated contributors, especially among patients with hypertension.

The Pearl River Delta region, as a major part of Guangdong-Hong Kong-Macao Great Bay Area, as one of China's most open and economically dynamic regions has been experiencing rapid economic development and urbanization. At the same time, medical and health services system in this region were booming. For example, the number of 
health care institutions increased by $14 \%$ from $2009(17,433)$ to 2015 $(19,870)$. Of note, the number increased to 25,023 in $2019(25,023)$, which was up $26 \%$ from 2015 [20]. It attracts not only many internal migrants from other cities, but also some residents from Hong Kong and Macao. Recent policy has proposed that residents of Hong Kong and Macao who resident in Guangdong Province could share the same treatment as mainland residents in education, medical care and old-age care[21].This new requirement means that cooperation between the region will no longer be limited in economy, but will also focus on social and livelihood issues. Under the special circumstances of "one country, two systems", it is especially crucial to explore the inequities in utilization of health services and promote the harmonious development of the Great Bay Area.

In such context, the present study is to measure socioeconomic inequalities and inequities in health services utilization by hypertensive patients in Pearl River Delta region in 2015 and 2019 and to establish whether they have changed. Using decomposition analysis, this study also provides new evidence on the contribution of socioeconomic variables to the distribution of health services utilization among hypertensive individuals. 


\section{Methods}

\section{Study design and subjects}

A data from the cross-sectional study based on community health survey conducted in Pearl River Delta Region of China in 2019 was used. Moreover, the data from the same survey we conducted in this region in 2015 was used for comparison. The two study samples were selected by a multistage and stratified random sampling method. The primary sampling units were designated as street communities and the second-stage sampling units were nominated as communities according to the economic level. All information were collected by trained staff though face-to-face interviews. After excluding cases with missing information, a total of 5507 and 5867 individuals participated in the survey in 2015 and 2019, respectively. Finally, 830 and 1166 hypertensive patients were included in this study in 2015 and 2019.

\section{Measurements}

\section{Dependent variables}

Two binary outcome variables of health services utilization by hypertensive patients were employed. The following questions of the hypertensive patients were asked: (1) Have you visited a doctor for 
outpatient care due to hypertension in the last 2 weeks? (2) Have you visited a doctor for inpatient care due to hypertension in the last year? The answers to questions were "yes" or "no".

\section{Independent and control variables}

In our study, age, gender and years of hypertension were classified as the need variables. Age was categorized into three year groups until 65 years and years of hypertension was also divided into three groups: 1-4, 5-9 and 10 or above.

There are economic status, educational level, employment status, marital status, household size, residential location, registration, health insurance and time to the nearest health facilities considered as socioeconomic variables (non-need variables). Economic status was constructed by using household income per household member, which was calculated by dividing the income for last year by household size, and then divided into five quintiles, which meant that the first and fifth quintile represent the poorest and richest wealth quintiles, respectively. Educational level was categorized into four groups: primary or below education, middle school, high school, and college or above education. Two employment categories and marital categories were employment and unemployment, married and single, respectively. Single includes 
unmarried, divorced, widowed and separated. Residential location and registration were divided into rural and urban, migrants and locals. Health insurance is based on whether the respondent is covered by the social health insurances.

\section{Concentration index}

The measurement of socioeconomic inequality in use of health service is based on a widely accepted index, appointed as the concentration index(CI). CI ranges from -1 to 1 , with an index of 0 equivalents to perfect equality. A positive CI signifies that a health or health care variable is more concentrated among the richer population and vice versa[22]. The index can be calculated by employing the equation as follows:

$$
C=\frac{2}{\mu} \operatorname{cov}\left(y_{i}, r_{i}\right)
$$

In equation (1), where $\mathrm{y}$ is the health variable (e.g. outpatient or inpatient service utilization in this study), $r_{i}$ is the fractional rank of the $i^{\text {th }}$ individual in the economic distribution, ranging from 0 to $1, \mu$ is the mean of $y$.

\section{Decomposition of inequality}

In order to analyze the contribution of independent variables of the 
inequality, we followed the method proposed by Wagstaff et al. to decompose CI[23]. Since the health variables analyzed in present study were binary variables, probit regressions were used to calculate the partial effects of each explanatory variable and the results should not be used to infer a direction of causality. The outcome variable $(\mathrm{y})$ is established as equation (2):

$$
y_{i}=a_{j}^{m}+\sum_{j} \beta_{j}^{m} x_{j i}+\sum_{k} \gamma_{k}^{m} z_{k i}+\varepsilon_{i}
$$

In equation (2), where $x_{j i}$ is the need variable (e.g. age, sex and health need), $z_{k i}$ is the non-need or socioeconomic variable (e.g. economic status, educational level and employment status); $\beta_{j}$ and $\gamma_{k}$ are the marginal effects $(d y / d x)$ of $x_{j}$ and $z_{k} ; \varepsilon_{i}$ indicates the error term. Then, CI for ycan be calculated as equation (3):

$$
\mathrm{C}=\sum_{j} \frac{\beta_{j}^{m} \overline{x_{j}}}{\mu} C_{j}+\sum_{k} \frac{\gamma_{k}^{m} \overline{z_{k}}}{\mu} C_{k}+\frac{G C_{\varepsilon}}{\mu}
$$

In equation (3), where $\overline{\chi_{j}}$ and $\overline{Z_{k}}$ are the means of $x_{j}$ and $z_{k}$; $C_{j}$ and $C_{k}$ are the concentration indexes of $x_{j}$ and $z_{k} ; \mu$ is the mean of $\mathrm{y}$ and $\mathrm{GC}_{\varepsilon}$ is the generalized concentration index of $\varepsilon$. This equation reveals the total concentration index is made up of two components. One of that is the residual component $\left(\frac{G_{\varepsilon}}{\mu}\right)$, which represents the inequality that is unexplained by the regressor. The other one is the explained component 
which is associated with two elements: (1) the impact of each determinant on health outcome, which is measured by its elasticity $\left(\eta=\frac{\beta_{j}^{m} \overline{x_{j}}}{\mu}\right.$ or $\left.\frac{\gamma_{k}^{m} \overline{z_{k}}}{\mu}\right)$; (2) the extent of unequal distribution of each determinant across economic groups, which is measured by $\mathrm{CI}[24]$. We then calculated the absolute contribution by multiplying the $\eta$ and CI with respect to that determinant. This value can be both positive and negative. We also calculated the percentage contribution of each regressor, which is equal to the absolute contribution divided by the total concentration index. Notably, the positive and negative contributions may be offset in the aggregate and the sum of percentage contribution and error term is equal to $100 \%$, therefore, the percentage contribution of several regressors may represent large positive and negative contributions, even exceeding $100 \%$.

\section{Horizontal inequity}

Horizontal inequity (HI) is the concentration index that measures the need-standardized health service utilization. It reflects socioeconomic inequality in the use of health services after controlling for the impacts of biological needs, such as age and sex [25]. HI can be computed as follows:

$$
\mathrm{HI}=C-\sum_{k}\left(\frac{\gamma_{k}^{m} \overline{x_{j}}}{\mu}\right) C_{j}
$$


In equation (4), similar to $\mathrm{CI}$, $\mathrm{HI}$ ranges from -1 to 1 . A positive $\mathrm{HI}$ suggests that the health service is more concentrated among the richer groups and vice versa.

\section{Decomposition change in inequality}

At this stage, we used Oaxaca-type decomposition to determine the extent to which change in inequality in health service usage by hypertensive patients between 2015 and 2019 which was owing to change in inequality in the determinants $[23,26,27]$. The decomposition formula is as follows(equation (5)):

$$
\Delta \mathrm{C}=\sum_{k} \eta_{k t}\left(c_{k t}-c_{k t-1}\right)+\sum_{k} c_{k t-1}\left(\eta_{k t}-\eta_{k t-1}\right)+\Delta \frac{G C_{\varepsilon t}}{\mu_{t}}
$$

In equation (5), where $\eta_{k t}$ and $\eta_{k t-1}$ represent the elasticity of explanatory variables in terms of health services utilization by hypertensive patients in 2015 and 2019, respectively. $c_{k t}$ and $c_{k t-1}$ are the normalized CIs of explanatory variables in these two years, respectively.

All analyses were performed on STATA 14.0. Statistical significance level was set as 0.05 .

\section{Results}




\section{Social demographic characteristics of respondents}

The characteristics of the study population are displayed in Table 1. From 2015 to 2019, the utilization of inpatient service due to hypertension increased greatly, with the growth rate at $34.20 \%$, whereas, a slight rise in the utilization of outpatient service, with a growth rate at $10.64 \%$. Nearly half of the patients aged 65 or over. More than half of the patients were suffering from hypertension for less than 5 years. Most of the respondents finished middle school. Over half of the participants were unemployed and married, and the household size is no more than 4 people. Most of the respondents with hypertension were the urban and local residents. The health insurance coverage increased from $97.71 \%$ to $99.94 \%$ during this period. In terms of the access to care, it took most of them less than 15 min to get to the nearest health facilities.

\section{Indexes for total inequality and horizontal inequity}

Table 1 also presents CIs and HIs for health services utilization by hypertensive patients. The CIs for outpatient and inpatient utilization, although all of them were positive, decreased from 0.1498 to 0.1198 , 0.1982 to 0.1648 , respectively, which meant that there were existed pro-rich inequalities in utilization of health services by hypertensive patients, but the inequalities shrank over time (Fig.1). However, as the 
need of health services have not been taken into account, inequality is not equivalent to really inequity. Then we calculated the horizontal inequity index. The HIs for outpatient and inpatient utilization decreased from 0.1478 to $0.1078,0.1956$ to 0.1390 , respectively, which provides the evidence of pro-rich inequities in utilization of health services. In other word, the rich could utilize more health services than the poor even after controlling for their different demands. Compared with the inequities in outpatient utilization, those in inpatient utilization were higher during 2015-2019.

\section{Decomposition of the inequalities}

A positive contribution to socioeconomic inequality means that the considered variable increases inequality. Table 2 and 3 reported the detailed decomposition of CIs for the health services utilization by hypertensive patients in the two survey-years. As can be seen from the results, the need variables of 65 years or over and years of hypertension more than 10 years displayed contribution in favor of the affluent. Among socioeconomic variables, economic status played the greatest contributory role to the inequalities favoring the rich in the utilization of health services. In addition, the contribution of household size also showed the same trend as the economic status. 
Notably, the percentage contribution of educational level to the uneven distribution of health services was positive in 2015 , nonetheless, that was negative in 2019 , especially in hypertensive patients completed college or above. In other words, the change of this factor reduced such pro-rich inequalities considerably. Furthermore, the positive contributions of the factors such as registration and time to the nearest health facilities declined to varying degrees over time, which also reduced the observed inequalities. For other remained variables such as employment status, residential location and health insurance, their contributions were relatively small during the observation period.

\section{Decomposition changes in inequalities between 2015 and 2019}

As shown in Table 1, the CIs of outpatient and inpatient utilization by hypertensive patients reduced by $0.0300(20.03 \%)$ and $0.0334(16.85 \%)$ from 2015 to 2019 . Then, the reductions were decomposed to seek contributing factors following by Oaxaca-type decomposition. The results were presented in Table 4. The second and fourth columns show changes in the amount of inequality in determinants; and the third and seventh columns show changes in elasticities of determinants.

From the changed CIs and elasticities for utilization of health services, we found that the three major contributors to reduce the 
decrease inequalities including the educational level, registration and time to the nearest health facilities. What's more, changes in employment status, residential location, marital status and health insurance could explain the reduction of CIs to some extent.

However, the changes of economic status accounted for the biggest contributor for the pro-rich inequalities. In addition, the changes of household size and the need variables of age and years of hypertension also pushed these inequalities into deterioration, especially in the utilization of inpatient .

\section{Discussion}

Our study explored the socioeconomic inequalities and inequities in the health services utilization by hypertensive patients in Pearl River Delta region of China between 2015 and 2019, and further quantifies the contribution of selected factors toward the inequalities. In addition, we also assessed the changes in the inequalities during the survey-period. The main findings were as follows: 1) obvious pro-rich inequalities and inequities in utilization of health services by hypertensive patients existed in Pearl River Delta region in both periods but they declined over time. 2) The changes in such inequalities were caused by the alteration in the interaction among the relevant determinants. 
The horizontal inequity indexes in 2015 and 2019 showed that there existed pro-rich inequities in utilization of health services by hypertensive patients in Pearl River Delta Region, which indicated that more health resources were utilized by the wealthier even after controlling of people's different needs. These findings were consistent with the previous studies $[28,29]$. However, the study displayed an excited sign that the degrees of inequities in use of health services have decreased over time. It could be explained by the measures taken by Chinese government to ensure equity to health access[30-32]. The funding subsidy for basic public health services increased from 15 to 40 RMB per capita in 2009 and 2015, even increased to 69 RMB per capita in 2019[33-35]. For hypertensive patients, the government provides at least one free follow-up visit every three months which includes health evaluation, syndrome surveillance, behavioral intervention, guidance on the use of medicines, and health education[36]. Naturally, these initiatives are supposed to help reduce the disease burden and improve the equities in health services utilization. However, in line with other studies [10, 37], the horizontal inequity indexes also revealed that more substantial inequities in inpatient utilization compared with outpatient utilization in both 2015 and 2019. It is possible that the price of outpatient utilization was relatively lower than inpatient utilization, most of the hypertension 
patients in lower economic status inclined to choose outpatient service at an affordable cost[37]. Besides, the reimbursement rate of hypertensive patients attending basic medical insurance is as high as more than $50 \%$, when they use outpatient services in secondary and lower designated primary medical institutions [38].

The decomposition analysis presented that economic status had the most significant association with inequalities in use of health services by hypertensive patients in Pearl River Delta Region of China during 2015-2019, furthermore, the positive contribution was increased in 2019. Actually, many studies have proved that the economic status was associated with health services utilization because a high income means a high payment capacity for care[39-41]. In addition, household size can help to explain the inequalities in health services utilization over this period. Hypertensive patients with smaller families were more likely to have a better use of health services. It was found that household size was significant and negatively correlated with utilization of formal medical services [42, 43]. Other socioeconomic variables such as educational level, employment status, residential location, registration and time to the nearest health facilities also can help to explain the uneven distribution of health services utilization over this period [44-47]. Generally, a variety of social factors related to an individual's socioeconomic status have an 
impact on person's health beliefs, which in turn influence one's health-seeking behavior [46] .

Oaxaca decomposition revealed that the changes in inequalities arise from the alteration in the interaction among the related determinants. Changes in residential location, registration, health insurance and time to the nearest health facilities pushed the inequalities towards equality line. These findings were likely to reflect the successful outcome of China's new health reform and the implementation of recent policies, which aimed at establishing a public health system covering both urban and rural residents and a universal health insurance system through affordable and equitable primary health care $[48,49]$. By the end of 2018, more than $96 \%$ of the Chinese were covered by health insurance and the reimbursement of medical insurance had already covered outpatient expenses for hypertension and another $16 \mathrm{NCDs}[50]$. In addition, the number of health facilities nationwide reached 1.014 million in 2019, an increase of 24,000 over 2015 [12, 51], even hypertensive patients living in townships and counties can easily get a variety of antihypertensive drugs at a zero profit mark-up from primary care facilities [52]. Significantly, the government of Guangdong Province has taken the lead in implementing the project of direct settlement of out-of-town medical treatment to ensure the migrants can obtain timely reimbursement [53]. These measures 
greatly reduced the burden of the migrants suffered from hypertension and bridged urban-rural disparity in health services utilization.

Additionally, the changes of employment status and educational level also helped to reduce such inequalities. A series of employment policies delivered by the government, such as increasing employment opportunities among the economically disadvantaged groups [54], played a role in promoting this trend. For the changes of educational level, a possible explanation may be that the proportion of young hypertensive individuals substantially increased in China[55], leading to an overall increase in patients' education.

However, we found that changes in economic status and household size pushed the inequalities in health services usage towards deterioration. In terms of economic status, it may link to the widening income gap in China[56], which expanding the gap in utilizing health services between the rich and the poor. For hypertensive patients, the change of their household size also may affect their health seeking behavior. With the implementation of the two-child policy in China[57], the average household size is expected to increase. Accordingly, proper measures may need to be taken to mitigate the potential negative effects of increasing household size [58]. 
Also, our findings revealed that changes in the need variable of age and years of hypertension made negative contributions to the reduction in such inequalities, particular in the utilization of inpatient. On the one hand, population ageing in China is intensified and the prevalence of hypertension increased with age in both men and women $[17,59]$. On the other hand, high blood pressure can reduce the elasticity of the vascular wall and aggravate the atherosclerosis with the development of the disease, causing a variety of heart, brain, kidney and other target organ damage[60]. Hypertensive patients who is older or had a longer year of hypertension may have high demands for health services, especially for inpatient service. Thereby, more health services were biased toward those people.

This study has some limitations that must be mentioned. Firstly, recall biases could not be avoidable in questionnaire-based surveys, especially the self-reported utilization of health services. Secondly, the supply-side variables used in the decomposition only include the time accessibility of health facilities, but lack of other factors, such as the price of health services. Finally, since the decomposition analysis is a descriptive statistic, we were not able to carry out a causality analysis. Despite the above limitations, this study has important policy implications for China towards reducing socioeconomic inequalities in 
health services utilization among patients suffered from NCDs.

\section{Conclusion}

Overall, the government's health strategies and policies have greatly promoted equitable distribution of health care, resulting in a reduction of inequities in health services utilization by hypertensive patients in Pearl River Delta region from 2015 to 2019, although the pro-rich inequities persists and the horizontal inequity in utilization of inpatient service is higher than that of outpatient service. The Oaxaca decomposition analysis reveals that the widening income gap and household size are the two main factors to exacerbate such inequalities. Health policies alone are not enough to tackle the inequalities and more comprehensive social policies are needed to protect the disadvantage groups, particularly the individuals suffered from chronic diseases.

\footnotetext{
Abbreviations

CI: Concentration index; HI: Horizontal inequity;
}

NCDs: Non-communicable diseases 


\section{Ethics approval and consent to participate}

The study was approved by the ethics committee of Guangdong Sociological Society. Written informed consent was obtained from each study participant before investigation.

\section{Consent for publication}

Informed consent was obtained from all individual participants included in the study.

\section{Availability of data and materials}

Data are available upon reasonable request. But our data might not be shared directly, because it's our team work and the data belongs to our team. Consent should be attained from team members.

\section{Competing interests}

The authors declare that they have no competing interests.

\section{Funding}

This study was supported by research grants from the National Natural Science Foundation of

China (81872584 and 81472941) and the Natural Science Foundation of Guangdong Province 
(2016A030313138).

\section{Authors' contributions}

YL, PW and JM conceived and designed the study. YL, MC, XP and JH contributed to collection of data, and analyzed the data and interpretation of the results. YL wrote the draft manuscript. NL, JM and PW critically commented the paper. JM, PW and YL finalized the manuscript with inputs from all authors. All of the authors approved the final version submitted for publication.

\section{Acknowledgements}

We gratefully acknowledge Dr Peixi Wang, Dr Jinxiang Ma, Dr Nan Liu, Mengjiao Cheng, Xin Peng and Junxuan Huang for their excellent work in study coordination, data collection and management.

\section{Author details}

${ }^{1}$ School of Public Health, Guangzhou Medical University, Guangzhou, Guangdong, China

${ }^{2}$ Pinghu Hospital, Health Science Center, Shenzhen University, Shenzhen, Guangdong, China

${ }^{3}$ General Practice Center, The Seventh Affiliated Hospital of Southern Medical University, Foshan, Guangdong, China 


\section{References:}

1. Penning MJ, Zheng C. Income Inequities in Health Care Utilization among Adults Aged 50 and Older. CAN J AGING 2016, 35(1):55-69.

2. Tang S, Meng Q, Chen L, Bekedam H, Evans T, Whitehead M. Tackling the challenges to health equity in China. LANCET 2008, 372(9648):1493-1501.

3. Braveman P. Health disparities and health equity: concepts and measurement. Annu Rev Public Health 2006, 27:167-194.

4. van Doorslaer E, Koolman X, Jones AM. Explaining income-related inequalities in doctor utilisation in Europe. HEALTH ECON 2004, 13(7):629-647.

5. Dorjdagva J, Batbaatar E, Dorjsuren B, Kauhanen J. Income-related inequalities in health care utilization in Mongolia, 2007/2008-2012. INT J EQUITY HEALTH 2015, 14:57.

6. Macinko J, Lima-Costa MF. Horizontal equity in health care utilization in Brazil, 1998-2008. INT J EQUITY HEALTH 2012, 11:33.

7. Devaux M. Income-related inequalities and inequities in health care services utilisation in 18 selected OECD countries. EUR J HEALTH ECON 2015, 16(1):21-33.

8. Vikum E, Krokstad S, Westin S. Socioeconomic inequalities in health care utilisation in Norway: the population-based HUNT3 survey. INT J EQUITY HEALTH 2012, 11:48. 
9. WHO. The World Health Report 2000. Geneva: WHO, 2000..

10. Xie X, Wu Q, Hao Y, Yin H, Fu W, Ning N, Xu L, Liu C, Li Y, Kang Z et al. Identifying determinants of socioeconomic inequality in health service utilization among patients with chronic non-communicable diseases in China. PLOS ONE 2014, 9(6):e100231.

11. Zhang X, Wu Q, Shao Y, Fu W, Liu G, Coyte PC. Socioeconomic inequities in health care utilization in China. Asia Pac J Public Health 2015, 27(4):429-438.

12. Statistical Bulletin of the People's Republic of China on National Economic and Social Development in 2019 [http://www.stats.gov.cn/tjsj/zxfb/202002/t20200228_1728913.html]. Accessed 28 Feb 2019.

13. Lai S, Shen C, Yang X, Zhang X, Xu Y, Li Q, Gao J, Zhou Z. Socioeconomic inequalities in the prevalence of chronic diseases and preventive care among adults aged 45 and older in Shaanxi Province, China. BMC PUBLIC HEALTH 2019, 19(1):1460.

14. Chow CK, Teo KK, Rangarajan S, Islam S, Gupta R, Avezum A, Bahonar A, Chifamba J, Dagenais G, Diaz R et al. Prevalence, awareness, treatment, and control of hypertension in rural and urban communities in high-, middle-, and low-income countries. JAMA 2013, 310(9):959-968.

15. Gaziano TA, Bitton A, Anand S, Weinstein MC. The global cost of nonoptimal blood pressure. J HYPERTENS 2009, 27(7):1472-1477.

16. Beaney T, Schutte AE, Tomaszewski M, Ariti C, Burrell LM, Castillo RR, Charchar FJ, 
Damasceno A, Kruger R, Lackland DT et al. May Measurement Month 2017: an analysis of blood pressure screening results worldwide. LANCET GLOB HEALTH 2018, 6(7):e736-e743.

17. Lu J, Lu Y, Wang X, Li X, Linderman GC, Wu C, Cheng X, Mu L, Zhang H, Liu J et al. Prevalence, awareness, treatment, and control of hypertension in China: data from 1.7 million adults in a population-based screening study (China PEACE Million Persons Project). LANCET 2017, 390(10112):2549-2558.

18. Chen WW, Gao RL, Liu LS, Zhu ML, Wang W, Wang YJ, Wu ZS, Li HJ, Gu DF, Yang YJ et al. China cardiovascular diseases report 2015: a summary. J GERIATR CARDIOL 2017, 14(1):1-10.

19. Duy KV, Van Minh H, Bao GK, Weinehall L, Ng N. Horizontal inequity in public health care service utilization for non-communicable diseases in urban Vietnam. Glob Health Action 2014, 7:24919.

20. A compendium of Health statistics of Guangdong Province in 2019 [http://wsjkw.gd.gov.cn/zd_ylfwxxgk/content/post_3002828.html]. Accessed on 27 May,2020.

21. The CPC Central Committee and the State Council issued the Outline of the Development Plan for the Guangdong-Hong Kong-Macao Greater Bay Area [http://www.gov.cn/zhengce/2019-02/18/content_5366593.htm\#1]. Accessed 18 Feb 2019. 
22. Wagstaff A, van Doorslaer E, Paci P. On the measurement of horizontal inequity in the delivery of health care. J HEALTH ECON 1991, 10(2):169-205, 247-249, 251-256.

23. Wagstaf A, van Doorslaer E, Watanabe N. On decomposing the causes of health sector inequalities with an application to malnutrition inequalities in Vietnam. $J$ Econ 2003, 112:207-223.

24. Shin H, Kim J. Differences in income-related inequality and horizontal inequity in ambulatory care use between rural and non-rural areas: using the 1998-2001 U.S. National Health Interview Survey data. INT J EQUITY HEALTH 2010, 9:17.

25. van Doorslaer E, Wagstaff A, van der Burg H, Christiansen T, De Graeve D, Duchesne I, Gerdtham UG, Gerfin M, Geurts J, Gross L et al. Equity in the delivery of health care in Europe and the US. J HEALTH ECON 2000, 19(5):553-583.

26. Oaxaca R. Male-female wage differentials in urban labor markets. INT ECON REV 1973, 14:693-709.

27. Amini RM RAKA. Changes in Socio-Economic Inequality in Neonatal Mortality in Iran Between 1995 - 2000 and 2005-2010: An Oaxaca decomposition analysis. Int J Health Policy Manag 2017, 6:219-228.

28. Zhao Y, Mahal AS, Haregu TN, Katar A, Oldenburg B, Zhang L. Trends and Inequalities in the Health Care and Hypertension Outcomes in China, 2011 to 2015. Int J Environ Res Public Health 2019, 16(22). 
29. Firmo JO, Barreto SM, Lima-Costa MF. The Bambui Health and Aging Study (BHAS): factors associated with the treatment of hypertension in older adults in the community. $C A D$ SAUDE PUBLICA 2003, 19(3):817-827.

30. Xiao N, Long Q, Tang X, Tang S. A community-based approach to non-communicable chronic disease management within a context of advancing universal health coverage in China: progress and challenges. BMC PUBLIC HEALTH 2014, 14 Suppl 2:S2.

31. Zhang D, Pan X, Li S, Liang D, Hou Z, Li Y, Shi L. Impact of the National Essential Public Health Services Policy on Hypertension Control in China. AM J HYPERTENS 2017, 31(1):115-123.

32. The CPC Central Committee and the State Council issued the Outline of the" Healthy China 2030" Plan [http://www.gov.cn/xinwen/2016-10/25/content_5124174.htm]. Accessed 25 0ct 2017.

33. Notice on Doing a Good Job of the National Basic Public Health Service Project in 2019 [http://www.nhc.gov.cn/jws/s7881/201909/83012210b4564f26a163408599072379.shtml]. Accessed 4 Sep 2019.

34. Notice on Doing a Good Job of the National Basic Public Health Service Project in 2015[http://www.nhc.gov.cn/jws/s3577/201506/61340494c00e4ae4bca0ad8411a724a9.shtml ]. Accessed on 11 June 2015.

35. China has launched and deployed nine national basic public health services 
[http://www.gov.cn/jrzg/2009-07/10/content_1362010.htm]. Accessed on 10 July 2009.

36. The Three Departments Issued a Notice on Doing a Good Job in the National Basic Public $\begin{array}{lllll}\text { Health } & \text { Service } & \text { Project } & \text { in } & 2017\end{array}$ [http://www.gov.cn/xinwen/2017-09/10/content_5223957.htm]. Accessed 10 Sep 2017.

37. Sun X, Zhang H, Hu X, Gu S, Zhen X, Gu Y, Huang M, Wei J, Dong H. Measurement and analysis of equity in health: a case study conducted in Zhejiang Province, China. INT J EQUITY HEALTH 2018, 17(1):36.

38. Interpretation of guiding opinions and policies on improving the mechanism of medication guarantee for hypertension and diabetes in urban and rural residents [http://www.nhsa.gov.cn/art/2019/10/10/art_38_1844.html]. Accessed on 10 Oct 2019.

39. Huang C, Liu CJ, Pan XF, Liu X, Li NX. Correlates of unequal access to preventive care in China: a multilevel analysis of national data from the 2011 China Health and Nutrition Survey. BMC HEALTH SERV RES 2016, 16:177.

40. Fan L, Liu J, Habibov NN. A Multilevel Logit Estimation on the Determinants of Utilization of Preventive Health Care and Healthy Lifestyle Practice in China. World Med Health Policy 2015, 7(4):309-328.

41. Wang Y, Wang J, Maitland E, Zhao Y, Nicholas S, Lu M. Growing old before growing rich: inequality in health service utilization among the mid-aged and elderly in Gansu and 
Zhejiang Provinces, China. BMC HEALTH SERV RES 2012, 12:302.

42. Liu D, Tsegai D. The New Cooperative Medical Scheme (NCMS) and its implications for access to healthcare and medical expenditure: evidence from rural China. ZEF Discussion Papers Dev Policy 2011, 155:1-42.

43. Liu H, Zhao Z. Impact of China's urban resident basic medical insurance on healthcare utilization and expenditure. Discussion Paper series, Forschungsinstitut zur Zukunft der Arbeit Vol. 6768. 2012:1-33.

44. Yang W. China's new cooperative medical scheme and equity in access to health care: evidence from a longitudinal household survey. INT J EQUITY HEALTH 2013, 12:20.

45. Zhu D, Guo N, Wang J, Nicholas S, Chen L. Socioeconomic inequalities of outpatient and inpatient service utilization in China: personal and regional perspectives. INT J EQUITY HEALTH 2017, 16(1):210.

46. Huang M, Zhang H, Gu Y, Wei J. Outpatient health-seeking behavior of residents in Zhejiang and Qinghai Province,China. BMC Public Health 2019, 19:967.

47. Li H, Wu Z, Hui X, Hu Y. Impact of local health insurance schemes on primary care management and control of hypertension: a cross-sectional study in Shenzhen, China. BMJ OPEN 2019, 9(10):e31098.

48. Chen Z. Launch of the health-care reform plan in China. LANCET 2009, 373(9672):1322-1324. 
49. Yip WC, Hsiao WC, Chen W, Hu S, Ma J, Maynard A. Early appraisal of China's huge and complex health-care reforms. LANCET 2012, 379(9818):833-842.

50. Notice on the Scope and Standards of Medical Fees Paid by Guangzhou Basic Medical Insurance Pooling Fund for 17 Designated Chronic Diseases Such as Hypertension [http://www.gz.gov.cn/gzybj/gkmlpt/content/5/5495/post_5495042.html\#14461]. Accessed 13 Sep 2013.

51. Statistical Bulletin of the People's Republic of China on National Economic and Social Development in 2015 [http://www.stats.gov.cn/tjsj/zxfb/201602/t20160229_1323991.html]. Accessed 29 Feb 2016.

52. Liu GG, Vortherms SA, Hong X. China's Health Reform Update. Annи Rev Public Health 2017, 38:431-448.

53. The Provincial Medical Insurance Bureau Comprehensively Promotes the "One-stop" Settlement of Medical Assistance and Direct Settlement of Medical Treatment in Other $\begin{array}{lllll}\text { Places } & \text { has } & \text { Reached } & \text { a } & \text { New }\end{array}$ [http://hsa.gd.gov.cn/gkmlpt/content/2/2590/post_2590453.html\#464]. Accessed 27 Aug 2019.

54. Notice of the People's Government of Guangdong Province on the Issuance of Certain Policies and Measures for Further Promoting Employment in Guangdong Province [http://www.gd.gov.cn/zwgk/wjk/qbwj/yf/content/post_164461.html]. Accessed 03 Dec 
2018.

55. Li D, Zeng X, Huang Y, Lei H, Li G, Zhang N, Huang W. Increased Risk of Hypertension in Young Adults in Southwest China: Impact of the 2017 ACC/AHA High Blood Pressure Guideline. CURR HYPERTENS REP 2019, 21(3):21.

56. Xie Y, Zhou X. Income inequality in today's China. Proc Natl Acad Sci U S A 2014, 111(19):6928-6933.

57. Chen Q. Relaxed population policy, family size and parental investments in children's education in rural Northwestern China. INT J EDUC DEV 2017, 54:39-50.

58. Zhang S, Chen Q, Zhang B. Understanding Healthcare Utilization In China Through The Andersen Behavioral Model: Review Of Evidence From The China Health And Nutrition Survey. Risk Manag Healthc Policy 2019, 12:209-224.

59. The Office of China National Committee on Aging.The general research report of Chinese strategic for dealing with population aging. Sci. Res Aging. 2015:34-38.

60. Ersahin M, Sehirli O, Toklu HZ, Suleymanoglu S, Emekli-Alturfan E, Yarat A, Tatlidede E, Yegen BC, Sener G. Melatonin improves cardiovascular function and ameliorates renal, cardiac and cerebral damage in rats with renovascular hypertension. J PINEAL RES 2009, 47(1):97-106. 
Table 1 Characteristics of study participants

\begin{tabular}{|c|c|c|c|c|}
\hline \multirow{2}{*}{ Variables } & \multicolumn{2}{|c|}{$2015 （ \mathrm{n}=830)$} & \multicolumn{2}{|c|}{$2019 （ n=1166 ）$} \\
\hline & $\mathrm{N}$ & $\%$ & $\mathrm{~N}$ & $\%$ \\
\hline \multicolumn{5}{|c|}{ Dependent variables } \\
\hline \multicolumn{5}{|c|}{ Outpatient utilization } \\
\hline No & 610 & 73.49 & 824 & 70.67 \\
\hline Yes & 220 & 26.51 & 342 & 29.33 \\
\hline \multicolumn{5}{|c|}{ Inpatient utilization } \\
\hline No & 690 & 83.13 & 902 & 77.36 \\
\hline Yes & 140 & 16.87 & 264 & 22.64 \\
\hline \multicolumn{5}{|c|}{ Need variables } \\
\hline \multicolumn{5}{|l|}{ Age(y) } \\
\hline $15-44$ & 79 & 9.52 & 134 & 11.49 \\
\hline $45-54$ & 117 & 14.10 & 184 & 15.78 \\
\hline $55-64$ & 224 & 26.99 & 296 & 25.39 \\
\hline$\geqq 65$ & 410 & 49.40 & 552 & 47.34 \\
\hline \multicolumn{5}{|l|}{ Gender } \\
\hline Female & 436 & 52.53 & 619 & 53.09 \\
\hline
\end{tabular}




\begin{tabular}{|c|c|c|c|c|}
\hline Male & 394 & 47.47 & 547 & 46.91 \\
\hline \multicolumn{5}{|c|}{ Years of hypertension (y) } \\
\hline $0-4$ & 467 & 56.27 & 665 & 57.03 \\
\hline $5-9$ & 209 & 25.18 & 323 & 27.70 \\
\hline$\geqq 10$ & 154 & 18.55 & 178 & 15.27 \\
\hline \multicolumn{5}{|c|}{ Socioeconomic variables } \\
\hline \multicolumn{5}{|l|}{ Economic status } \\
\hline Poorest & 169 & 20.36 & 233 & 19.98 \\
\hline Poorer & 170 & 20.48 & 235 & 20.15 \\
\hline Middle & 165 & 19.88 & 234 & 20.07 \\
\hline Richer & 165 & 19.88 & 233 & 19.98 \\
\hline Richest & 161 & 19.40 & 231 & 19.81 \\
\hline \multicolumn{5}{|l|}{ Educational level } \\
\hline Primary or below & 372 & 44.82 & 529 & 45.37 \\
\hline Middle school & 257 & 30.96 & 358 & 30.70 \\
\hline High school & 146 & 17.59 & 198 & 16.98 \\
\hline College or above & 55 & 6.63 & 81 & 6.95 \\
\hline \multicolumn{5}{|l|}{ Employment status } \\
\hline Unemployed & 555 & 66.87 & 723 & 62.01 \\
\hline
\end{tabular}




\begin{tabular}{|c|c|c|c|c|}
\hline Employed & 275 & 33.13 & 443 & 37.99 \\
\hline \multicolumn{5}{|l|}{ Marital status } \\
\hline Single & 137 & 16.51 & 180 & 15.44 \\
\hline Married & 693 & 83.49 & 986 & 84.56 \\
\hline \multicolumn{5}{|c|}{ Household size } \\
\hline$\leqq 4$ & 596 & 71.81 & 774 & 66.38 \\
\hline$>4$ & 234 & 28.19 & 392 & 33.62 \\
\hline \multicolumn{5}{|c|}{ Residential location } \\
\hline Rural & 323 & 38.92 & 511 & 43.83 \\
\hline Urban & 507 & 61.08 & 655 & 56.17 \\
\hline \multicolumn{5}{|l|}{ Registration } \\
\hline Migrants & 214 & 25.78 & 295 & 25.30 \\
\hline Locals & 616 & 74.22 & 871 & 74.70 \\
\hline \multicolumn{5}{|c|}{ Insurance scheme } \\
\hline No & 19 & 2.29 & 7 & 0.60 \\
\hline Yes & 811 & 97.71 & 1159 & 99.40 \\
\hline \multicolumn{5}{|c|}{ Time to the nearest health facilities(min) } \\
\hline$\leqq 15$ & 707 & 85.18 & 1082 & 92.80 \\
\hline$>15$ & 123 & 14.82 & 84 & 7.20 \\
\hline
\end{tabular}




$\begin{array}{lccc}\text { CI of outpatient } \quad \text { utilization } & 0.1498 & 0.1198 \\ \text { HI of outpatient } & \text { utilization } & 0.1478 & 0.1078 \\ \text { CI of inpatient } \quad \text { utilization } & 0.1982 & 0.1648 \\ \text { HI of inpatient } \quad \text { utilization } & 0.1956 & 0.1390\end{array}$

Note: $\mathrm{Cl}$ : Concentration index; $\mathrm{HI}$ : Horizontal inequity index

Table 2 Decomposition of CI in outpatient utilization by hypertensive patients in $2015-2019$

\begin{tabular}{|c|c|c|c|c|c|c|}
\hline \multirow{2}{*}{ Variables } & \multicolumn{3}{|c|}{$2015 （ \mathrm{n}=830 ）$} & \multicolumn{3}{|c|}{$2019 （ n=1166)$} \\
\hline & $d y / d x$ & Con. & $\%$ con. & $d y / d x$ & Con. & $\%$ con \\
\hline \multicolumn{7}{|l|}{$\operatorname{Age}(y)$} \\
\hline $15-44$ & Ref. & & & & & \\
\hline $45-54$ & 0.1051 & -0.0024 & -1.60 & -0.0461 & 0.0012 & 1.04 \\
\hline $55-64$ & 0.1037 & 0.0018 & 1.18 & 0.0955 & -0.0004 & -0.30 \\
\hline$\geqq 65$ & $0.1983^{*}$ & 0.0017 & 1.13 & $0.1799 *$ & 0.0128 & 10.71 \\
\hline sum & & 0.0011 & 0.71 & & 0.0137 & 11.44 \\
\hline \multicolumn{7}{|l|}{ Gender } \\
\hline Female & Ref. & & & & & \\
\hline
\end{tabular}




\begin{tabular}{|c|c|c|c|c|c|c|}
\hline Male & -0.0314 & -0.0012 & -0.80 & -0.0015 & $<0.0001$ & 0.04 \\
\hline \multicolumn{7}{|c|}{ Years of hypertension (y) } \\
\hline \multicolumn{7}{|l|}{$1-4$} \\
\hline $5-9$ & $0.2346^{*}$ & -0.0006 & -0.39 & 0.0526 & -0.0012 & -0.99 \\
\hline$\geqq 10$ & $0.1662^{*}$ & 0.0027 & 1.81 & $0.0938^{*}$ & 0.0042 & 3.48 \\
\hline sum & & 0.0021 & 1.42 & & 0.0030 & 2.49 \\
\hline \multicolumn{7}{|l|}{ Economic status } \\
\hline Poorest & Ref. & & & & & \\
\hline Poorer & 0.0404 & -0.0061 & -4.06 & 0.0596 & -0.0082 & -6.81 \\
\hline Middle & $0.2616^{*}$ & 0.0010 & 0.66 & $0.1661^{*}$ & 0.0001 & 0.10 \\
\hline Richer & $0.3095^{*}$ & 0.0477 & 31.82 & $0.3623^{*}$ & 0.0497 & 41.46 \\
\hline Richest & $0.2344^{*}$ & 0.0696 & 46.43 & $0.3217 *$ & 0.0872 & 72.80 \\
\hline sum & & 0.1121 & 74.85 & & 0.1288 & 107.54 \\
\hline \multicolumn{7}{|l|}{ Educational level } \\
\hline Primary or below & Ref. & & & & & \\
\hline Middle school & 0.0100 & -0.0002 & -0.11 & 0.0476 & -0.0016 & -1.35 \\
\hline High school & $0.1208^{*}$ & 0.0055 & 3.65 & $0.2249 *$ & 0.0003 & 0.22 \\
\hline College or above & $0.3767 *$ & 0.0152 & 10.16 & $0.2186^{*}$ & -0.0011 & -0.92 \\
\hline sum & & 0.0205 & 13.70 & & -0.0025 & -2.05 \\
\hline
\end{tabular}


Employment status

$\begin{array}{lllllll}\text { Unemployed } & \text { Ref. } \\ & \\ \text { Employed } & 0.0024 & -0.0002 & -0.13 & 0.0809 & -0.0053 & -4.41\end{array}$

Marital status

Single Ref.

$\begin{array}{lllllll}\text { Married } & 0.0070 & 0.0002 & 0.16 & 0.0032 & <0.0001 & -0.03\end{array}$

Household size

$\leqq 4 \quad$ Ref.

$\begin{array}{lllllll}>4 & -0.0951 * & 0.0053 & 3.53 & -0.0842 * & 0.0064 & 5.35\end{array}$

Residential location

Rural Ref.

$\begin{array}{lllllll}\text { Urban } & 0.0730 * & 0.0054 & 3.63 & 0.0289 & 0.0009 & 0.78\end{array}$

Registration

Migrants Ref.

$\begin{array}{lllllll}\text { Locals } & 0.1491^{*} & 0.0165 & 11.01 & 0.2401 * & 0.0050 & 4.16\end{array}$

Health insurance

No Ref.

$\begin{array}{lllllll}\text { Yes } & 0.0966 & 0.0006 & 0.38 & 0.0261 & <0.0001 & 0.04\end{array}$

Time to the nearest health facilities(min) 


\begin{tabular}{lllllll}
\hline$\leqq 15$ & Ref. & & & & & \\
& & & & & \\
$>15$ & $-0.2229 *$ & 0.0213 & 14.20 & $-0.2302 *$ & 0.0016 & 1.30 \\
\hline
\end{tabular}

Note: (1) $d y / d x$ : Partial effect in probit regression model; Con.: The absolute contribution of each determinant; \%con.: The percentage contribution of each determinant to the total concentration index; (2) *p< 0.05

Table 3 Decomposition of CI in inpatient utilization by hypertensive patients in 2015-2019

\begin{tabular}{|c|c|c|c|c|c|c|}
\hline \multirow{2}{*}{ Variables } & \multicolumn{3}{|c|}{$2015 （ n=830)$} & \multicolumn{3}{|c|}{$2019 （ n=1166)$} \\
\hline & $d y / d x$ & Con. & $\%$ con. & $d y / d x$ & Con. & $\%$ con. \\
\hline \multicolumn{7}{|l|}{$\operatorname{Age}(y)$} \\
\hline $15-44$ & Ref. & & & & & \\
\hline $45-54$ & $0.1132 *$ & -0.0037 & -1.88 & -0.0097 & 0.0005 & 0.30 \\
\hline $55-64$ & 0.0696 & 0.0012 & 0.58 & 0.1022 & -0.0004 & -0.27 \\
\hline$\geqq 65$ & $0.1308^{*}$ & 0.0018 & 0.88 & $0.3566^{*}$ & 0.0158 & 9.56 \\
\hline sum & & -0.0008 & -0.41 & & 0.0158 & 9.58 \\
\hline \multicolumn{7}{|l|}{ Gender } \\
\hline Female & Ref. & & & & & \\
\hline
\end{tabular}




\begin{tabular}{|c|c|c|c|c|c|c|}
\hline Male & -0.0234 & -0.0014 & -0.71 & 0.0827 & -0.0015 & -0.94 \\
\hline \multicolumn{7}{|c|}{ Years of hypertension (y) } \\
\hline $1-4$ & Ref. & & & & & \\
\hline $5-9$ & $0.1662 *$ & -0.0006 & -0.32 & 0.0203 & -0.0005 & -0.29 \\
\hline$\geqq 10$ & $0.2395 *$ & 0.0061 & 3.09 & $0.1401 *$ & 0.0120 & 7.26 \\
\hline sum & & 0.0055 & 2.77 & & 0.0115 & 6.96 \\
\hline \multicolumn{7}{|l|}{ Economic status } \\
\hline Poorest & Ref. & & & & & \\
\hline Poorer & -0.0127 & 0.0031 & 1.58 & -0.0016 & 0.0003 & 0.19 \\
\hline Middle & $0.1322 *$ & 0.0008 & 0.40 & $0.1519 *$ & 0.0002 & 0.09 \\
\hline Richer & $0.1774 *$ & 0.0429 & 21.65 & $0.2577 *$ & 0.0518 & 31.46 \\
\hline Richest & $0.2235^{*}$ & 0.1042 & 52.59 & $0.3086^{*}$ & 0.1239 & 75.17 \\
\hline sum & & 0.1511 & 76.22 & & 0.1762 & 106.92 \\
\hline \multicolumn{7}{|l|}{ Educational level } \\
\hline Primary or below & Ref. & & & & & \\
\hline Middle school & 0.0125 & -0.0003 & -0.16 & 0.0241 & -0.0008 & -0.48 \\
\hline High school & $0.0786^{*}$ & 0.0056 & 2.82 & $0.0676^{*}$ & 0.0001 & 0.08 \\
\hline College or above & $0.1605 *$ & 0.0102 & 5.14 & 0.0266 & -0.0006 & -0.34 \\
\hline sum & & 0.0155 & 7.80 & & -0.0012 & -0.73 \\
\hline
\end{tabular}


Employment status

Unemployed

Employed

Marital status

Single

Married

$>4$

Residential location

Rural

Urban

Registration

Migrants

Locals

$0.1013 *$

0.0176

8.88

0.3870

0.0032

1.91

Ref.

0.0403

0.0004

0.19

0.1442

$-0.0006$

$-0.34$

Ref.

$-0.0429 *$

0.0037

$-0.1431 *$

0.0095

5.76

Health insurance

No

Ref.

Yes

0.0210

0.0002

0.10

0.0095

$-0.0006$

$-0.35$

Time to the nearest health facilities(min) 


\begin{tabular}{lllllll}
\hline$\leqq 15$ & Ref. & & & & & \\
& & & & & & \\
$>15$ & $-0.0708^{*}$ & 0.0106 & 5.36 & -0.0194 & 0.0005 & 0.32 \\
\hline
\end{tabular}

Note: (1)dy/dx: Partial effect in probit regression mode; Con.: The absolute contribution of each determinant; \%con.: The percentage contribution of each determinant to the total concentration index; (2) *p $<0.05$

Table 4 Oaxaca-type decomposition for changes in inequalities in health services utilization by hypertensive patients, 2015-2019

\begin{tabular}{|c|c|c|c|c|c|c|c|c|}
\hline \multirow{2}{*}{ Variables } & \multicolumn{4}{|c|}{ Outpatient utilization } & \multicolumn{4}{|c|}{ Inpatient utilization } \\
\hline & $\Delta c^{*} \eta_{k t-1}$ & $\Delta \eta^{*} c_{k t-1}$ & Total & $\%$ & $\Delta c^{*} \eta_{k t-1}$ & $\Delta \eta * c_{k t-1}$ & Total & $\%$ \\
\hline \multicolumn{9}{|l|}{$\operatorname{Age}(y)$} \\
\hline $15-44$ & Ref. & & & & & & & \\
\hline $45-54$ & 0.0002 & 0.0035 & 0.0036 & -12.13 & 0.0001 & 0.0041 & 0.0042 & -12.85 \\
\hline $55-64$ & -0.0017 & -0.0004 & -0.0021 & 7.08 & -0.0022 & 0.0005 & -0.0016 & 5.01 \\
\hline$\geqq 65$ & 0.0115 & -0.0004 & 0.0111 & -37.12 & 0.0141 & -0.0001 & 0.0140 & -43.91 \\
\hline sum & & & & -42.17 & & & & -51.75 \\
\hline Gender & & & & & & & & \\
\hline
\end{tabular}




\begin{tabular}{|c|c|c|c|c|c|c|c|c|}
\hline Female & Ref. & & & & & & & \\
\hline Male & 0.0001 & 0.0011 & 0.0012 & -4.14 & -0.0033 & 0.0032 & -0.0001 & 0.13 \\
\hline \multicolumn{9}{|c|}{ Years of hypertension (y) } \\
\hline $1-4$ & Ref. & & & & & & & \\
\hline $5-9$ & -0.0011 & 0.0004 & -0.0006 & 2.01 & -0.0004 & 0.0006 & 0.0002 & -0.81 \\
\hline$\geqq 10$ & 0.0030 & -0.0016 & 0.0015 & -4.87 & 0.0087 & -0.0029 & 0.0058 & -20.68 \\
\hline sum & & & & -2.86 & & & & -21.49 \\
\hline \multicolumn{9}{|l|}{ Economic status } \\
\hline Poorest & Ref. & & & & & & & \\
\hline Poorer & -0.0002 & -0.0019 & -0.0021 & 6.91 & $<0.0001$ & -0.0028 & -0.0028 & 8.61 \\
\hline Middle & -0.0005 & -0.0004 & -0.0009 & 2.92 & -0.0006 & $<0.0001$ & -0.0006 & 1.87 \\
\hline Richer & -0.0010 & 0.0030 & 0.0020 & -6.68 & -0.0011 & 0.0100 & 0.0089 & -27.79 \\
\hline Richest & -0.0009 & 0.0186 & 0.0177 & -58.87 & -0.0013 & 0.0209 & 0.0196 & -55.67 \\
\hline sum & & & & -55.72 & & & & -72.98 \\
\hline \multicolumn{9}{|l|}{ Educational level } \\
\hline Primary or below & Ref. & & & & & & & \\
\hline Middle school & -0.0009 & -0.0005 & -0.0015 & 4.88 & -0.0005 & $<0.0001$ & -0.0005 & 1.72 \\
\hline High school & -0.0086 & 0.0034 & -0.0052 & 17.32 & -0.0045 & -0.0010 & -0.0054 & 16.27 \\
\hline College or above & -0.0095 & -0.0069 & -0.0163 & 54.39 & -0.0049 & -0.0059 & -0.0108 & 32.34 \\
\hline
\end{tabular}




\begin{tabular}{|c|c|c|c|c|c|c|c|c|}
\hline sum & & & & 76.59 & & & & 50.33 \\
\hline \multicolumn{9}{|c|}{ Employment status } \\
\hline Unemployed & Ref. & & & & & & & \\
\hline Employed & 0.0016 & -0.0067 & -0.0051 & 16.97 & -0.0024 & 0.0002 & -0.0022 & 9.79 \\
\hline \multicolumn{9}{|l|}{ Marital status } \\
\hline Single & Ref. & & & & & & & \\
\hline Married & $<0.0001$ & -0.0003 & -0.0003 & 0.92 & 0.0001 & -0.0010 & -0.0009 & 2.92 \\
\hline \multicolumn{9}{|l|}{ Household size } \\
\hline$\leqq 4$ & Ref. & & & & & & & \\
\hline$>4$ & 0.0014 & -0.0002 & 0.0011 & -3.74 & 0.0020 & 0.0037 & 0.0058 & -17.49 \\
\hline \multicolumn{9}{|c|}{ Residential location } \\
\hline Rural & Ref. & & & & & & & \\
\hline Urban & -0.0009 & -0.0036 & -0.0045 & 15.00 & -0.0014 & -0.0001 & -0.0015 & 4.32 \\
\hline \multicolumn{9}{|l|}{ Registration } \\
\hline Migrants & Ref. & & & & & & & \\
\hline Locals & -0.0192 & 0.0077 & -0.0115 & 38.36 & -0.0121 & -0.0023 & -0.0145 & 43.34 \\
\hline \multicolumn{9}{|c|}{ Health insurance } \\
\hline No & Ref. & & & & & & & \\
\hline Yes & -0.0001 & -0.0004 & -0.0005 & 1.76 & -0.0006 & -0.0002 & -0.0008 & 0.57 \\
\hline
\end{tabular}


Time to the nearest health facilities(min)

$\leqq 15 \quad$ Ref

$\begin{array}{lllllllll}>15 & -0.0081 & -0.0116 & -0.0197 & 65.73 & -0.0028 & -0.0073 & -0.0101 & 29.98\end{array}$

Fig.1 title: Concentration curves for use of health services, 2015

versus 2019 
Figures

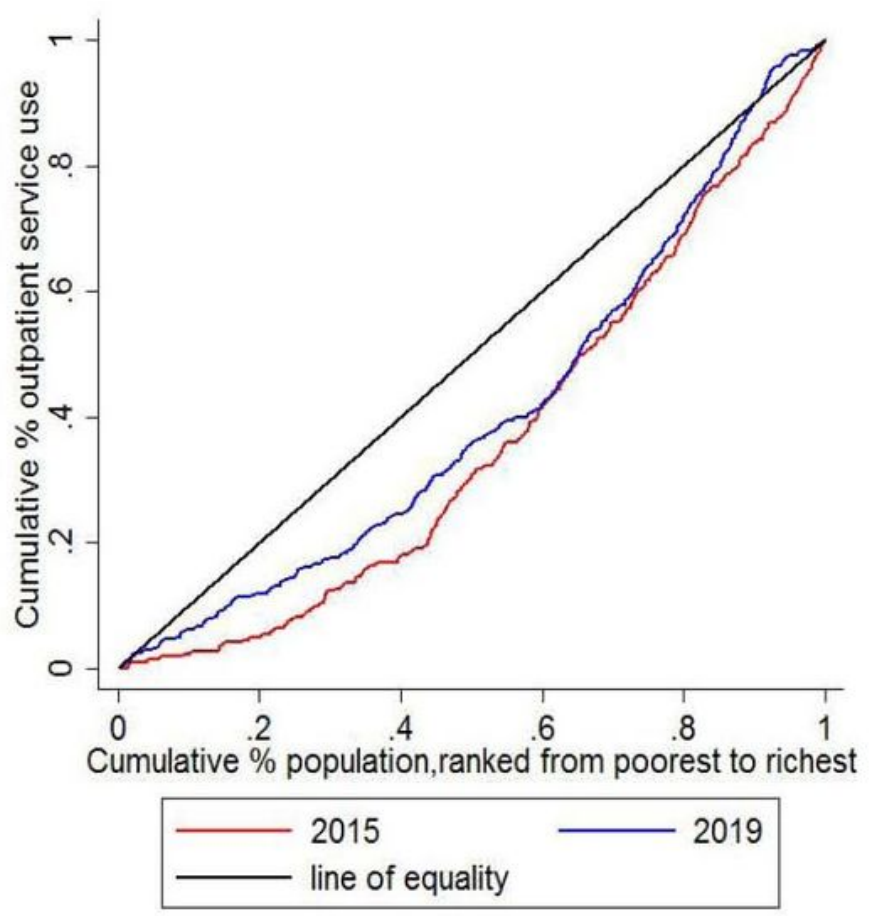

a.Concentration curves for use of outpatient services

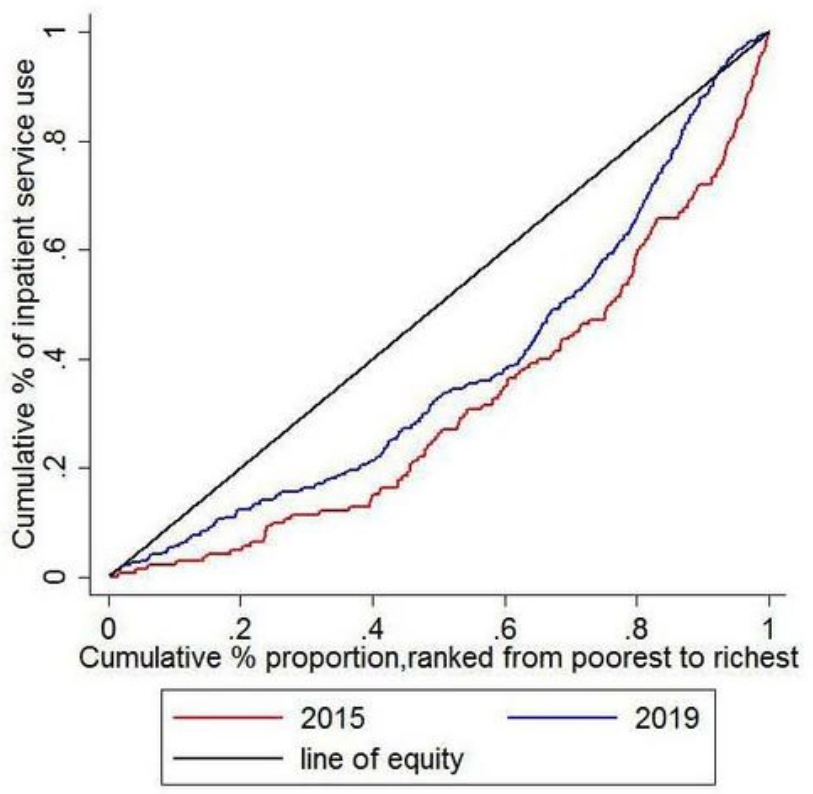

b.Concentration curves for use of inpatient services

Figure 1

Concentration curves for use of health services, 2015 versus 2019 